\title{
Effectiveness of progressive relaxation and emotional regulation on quality of life of heart patients
}

\author{
$\underline{\text { SY. Mohammadi }}{ }^{1}$, Sh. Ahmadi²
}

\author{
${ }^{1}$ Department of Psychology, Payame Noor University, Bushehr, Iran \\ ${ }^{2}$ Payam Noor University, Assaluyeh, Iran \\ Corresponding Address: Seyed Younes Mohammadi, Department of Psychology, Payame Noor University, Bushehr, Iran \\ Tel: +98-917-7751851; Email: mohammadi_1355@yahoo.com \\ Received: 19 Aug 2018; Accepted: 17 Nov 2018
}

*bstract

Background: One of the major problems in the world are Cardiovascular diseases and it is the reason of $30 \%$ of the deaths.

Objective: The current study aimed to investigate the effectiveness of progressive relaxation and emotional regulation on quality of life of elderly heart patients.

Methods: This semi-experimental research was conducted with pre-posttest design with an experimental and control group in 2016-17. The population consisted of all elderly heart patients living in Dashti city who have been admitted to the hospital. Forty-five elderly heart patients were selected and randomly assigned to two experimental and control groups $(n=15)$. The control group did not receive any intervention. An interventional programs (progressive muscle relaxation and emotional regulation) were performed in eight sessions for 40 minutes for experimental groups. To collect data, the World Health Organization Quality-of-Life scale (WHOQOL-BREF) were used. Data were analyzed and represented as mean, standard deviation, and ANCOVA.

Findings: The quality of life in two experimental groups (progressive muscle relaxation and emotional regulation) compared to the control group, at posttest were increased $(\mathrm{P}<0.05)$. The average scores of quality of life was significantly increased in the progressive muscle relaxation group rather than emotion regulation training group in post-test stages $(\mathrm{P}<0.01)$.

Conclusion: The results showed that progressive muscle relaxation and emotional regulation can be effective to treat and work with the elderly heart patients.

Keywords: Muscle relaxation, Emotion, Quality of life, Cardiovascular diseases, Elderly

Citation: Mohammadi SY, Ahmadi Sh. Effectiveness of progressive relaxation and emotional regulation on quality of life of heart patients. J Qazvin Univ Med Sci 2018; 22(5): 59-69. 


\section{مقايسه اثربخشى روش آرامسازى عضلانى يِيشرونده و تنظيم هيجانى بر كيفيت زندَّى بيماران قلبى سالمند}

دكتر سيد يونس محمدى'، شريفه احمدى'

أروره روانشناسى دانشخاه يِيام نور، بوشهر، ايران

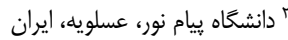

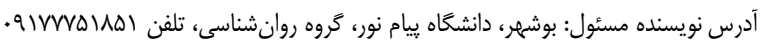

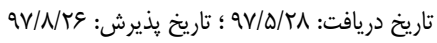

مقدمه: بيمارى هاى قلبى يكى از مشكلات بزركى در سراسر دنيا و علت •ب درصد از مركَها به حساب مى آيند.

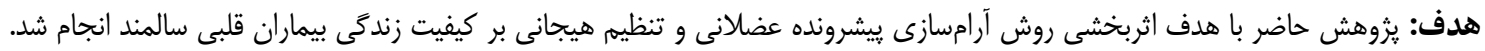

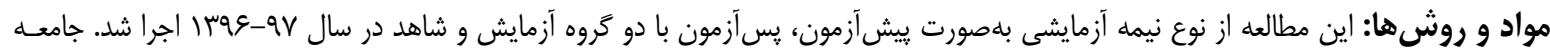

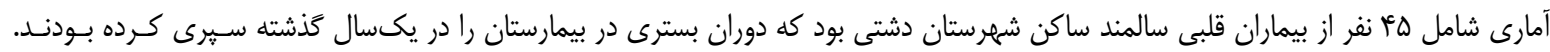

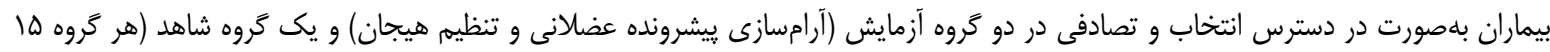

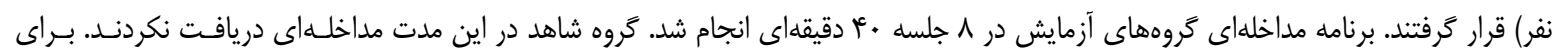

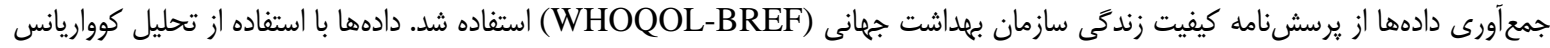
تك متغيره تجزيه و تحليل شدند.

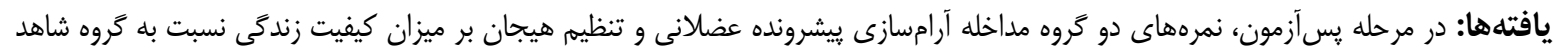

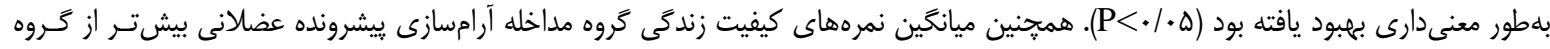

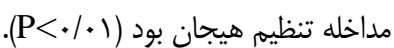

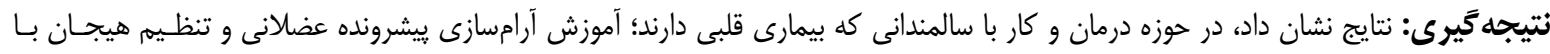

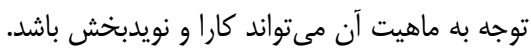

كليدوازهها: آرامسازى عضلانى، هيجان، كيفيت زندگى، بيمارىهاى قلبى- عروقى، سالمند

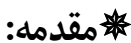

IV سوم تمام مرگهاى بالاى هـ سال است كه هر ساله ميليون نفر را به كام مرگ مىفرسـتد و يـيشبينسى شــده

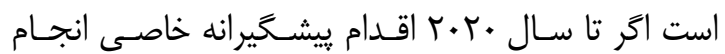

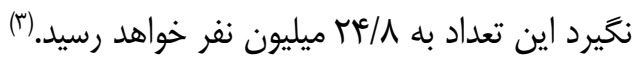
شواهد بسيار زيادى نشان مىدهد مبتلايان به بيمارى قلبى با يِيامدهاى فراوان جسمى، روانى، عاطفى و روحسى

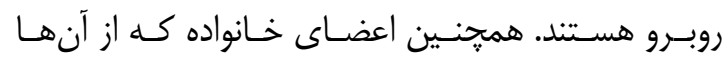
مراقبت مى كنند نيز با مشكاتلات فراوانى روبرو مىشوند.(ז) مجموعه اين علايم باعث محدوديتهايى در فعاليتهـاى مريى
جمعيت سالمندان در ايـران و جهـان رو بــه افـزايش

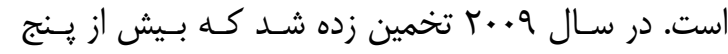

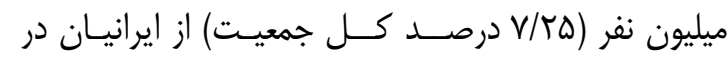

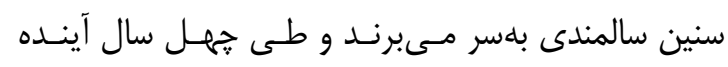

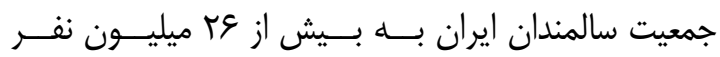

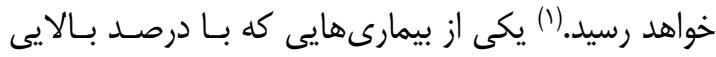

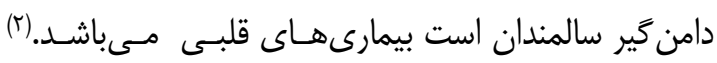

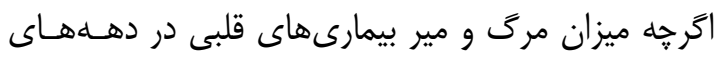

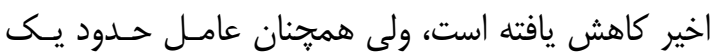


يا ه جلسه احساس خواهد شد. توصيه ب يا ب بـار تمـرين

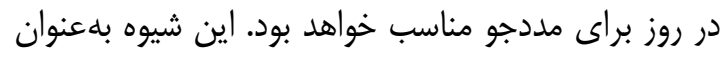

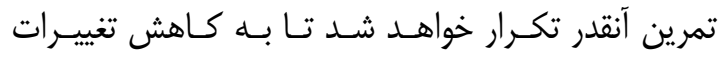

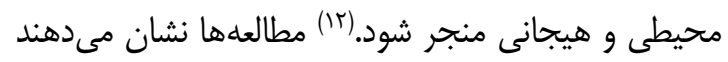

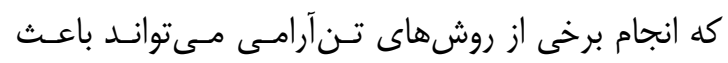

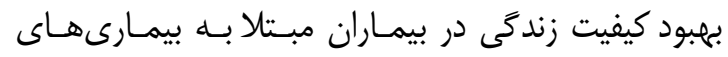

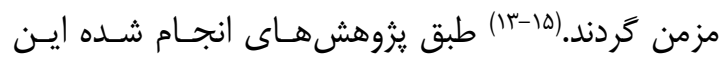

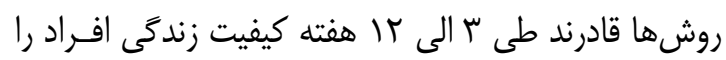
تحت تأثير قرار دهند.(19)

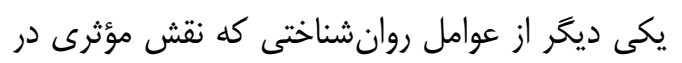

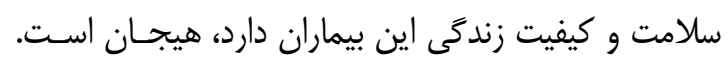

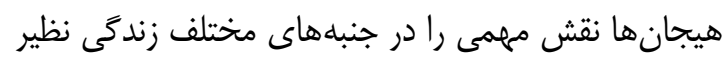

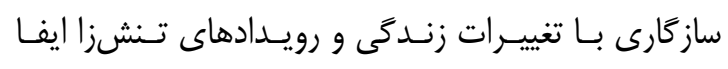

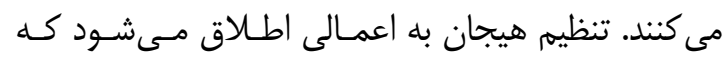

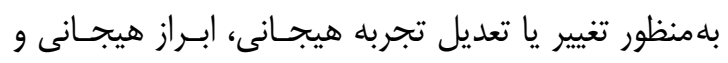

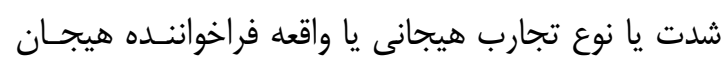

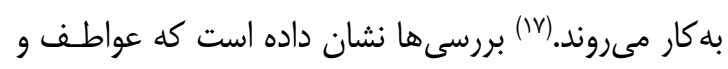

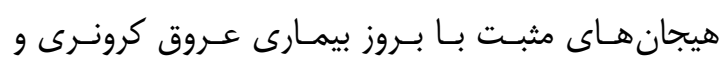

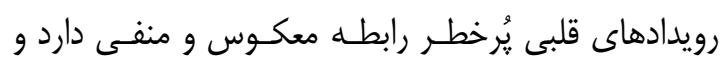
هيجان هاى خاصى مانند اضطراب بلهصورت بالقوه عوامـل رلـ

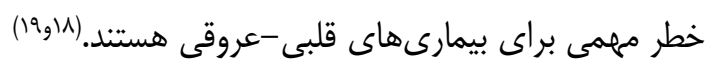

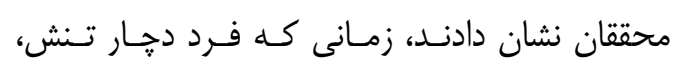

عصبانيت يا اضطراب مىشود دستخاه عصبى سمياتيك به ديه

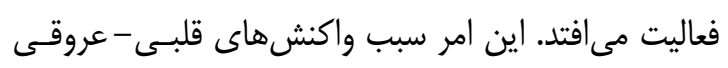

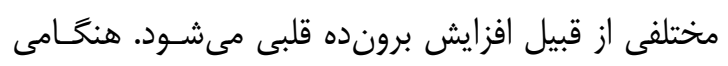

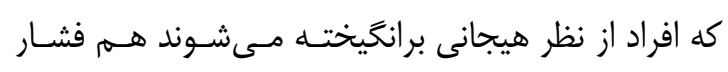

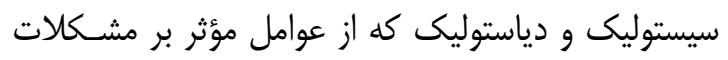

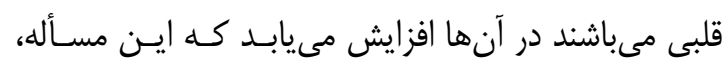

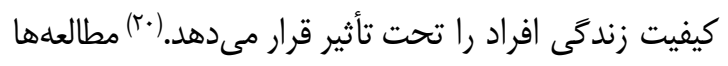

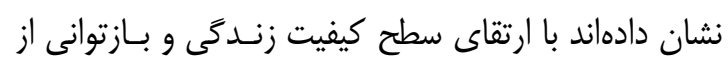

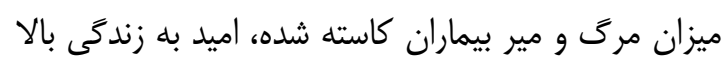

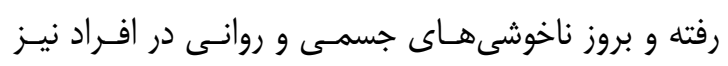

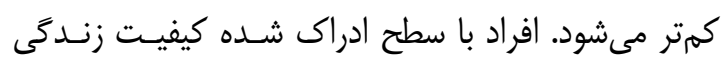

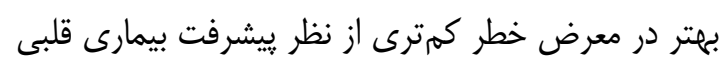

روزمره، انجام امور شخصى و اجتماعى بيمار مى گردد كـهـ

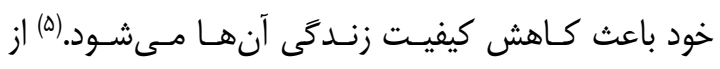

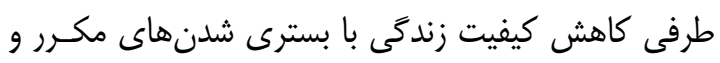

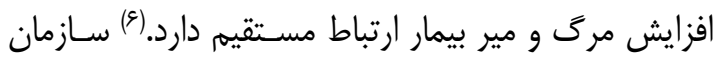

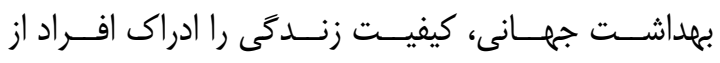

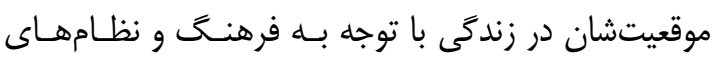

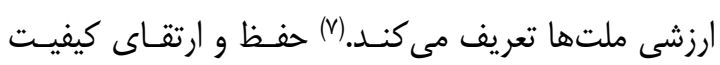

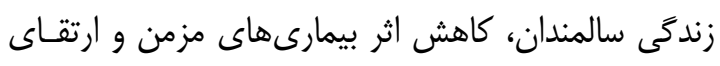

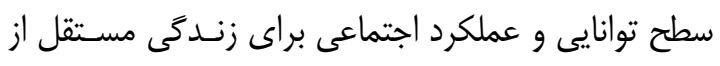

اهداف نظام سلامتى هر كشورى محسوب مى شود..(1) در روند درمان و مراقبت از بيماران قلبى سالمند بايسـ

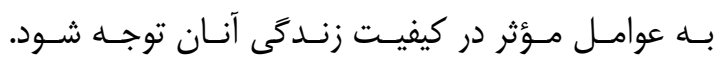

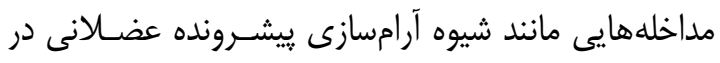

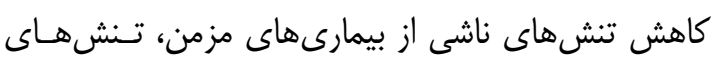

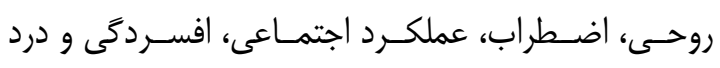

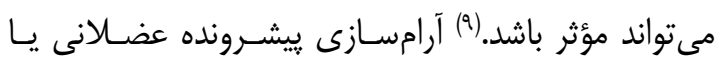

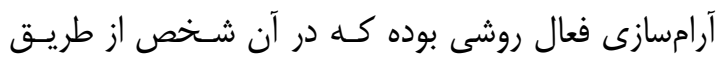

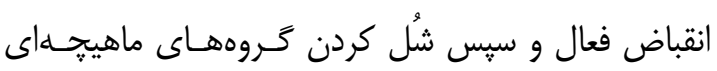

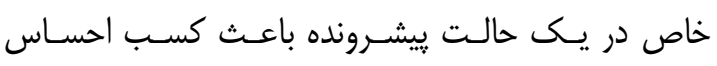

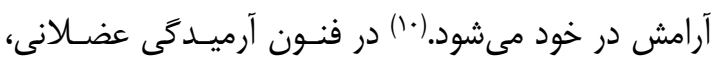

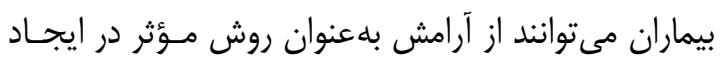
اين احساس كه بر نشانههاى خود كنترل دارنـد، اسـتفاده إنـاه

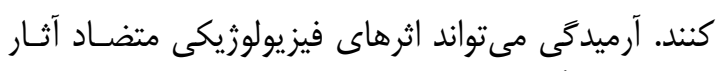

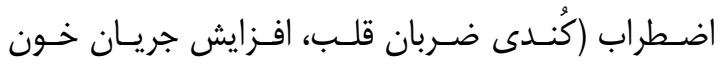

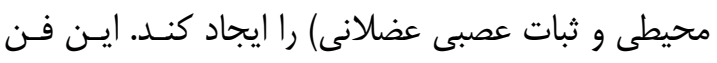

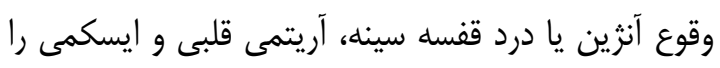

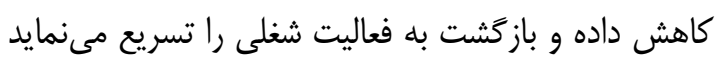

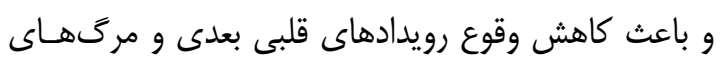

قلبى مىشود.) آموزش آرامسازى مداخلهاى غيردارويى بودهد كه براى

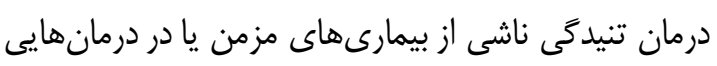

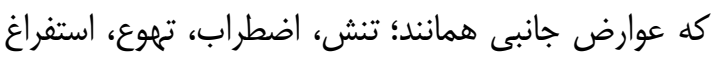

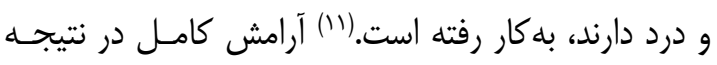

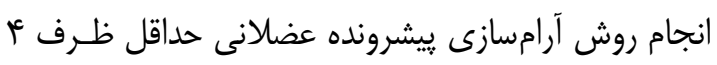


تصادفى به دو گروه آزمايش (آموزش آرامسازى ييشرونده

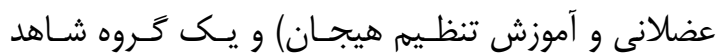
طبقهبندى شدند. در همه گروهها اعم از دو گروه آزمايش و گروه شاهد

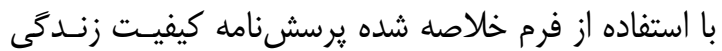
سازمان بهداشت جهانى ييش آزمون اجرا شد. در صورتى كه

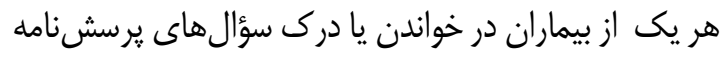

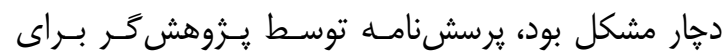

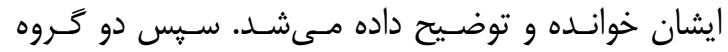

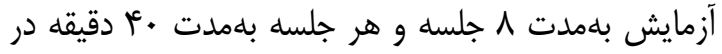

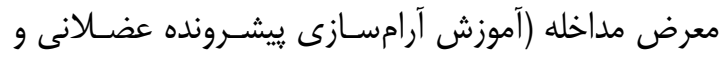

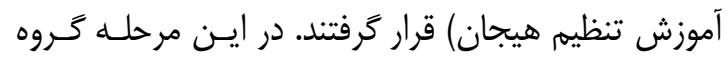
شاهد هيج گونه مداخلهاى دريافت نكرد. در קيايان جلسهها،

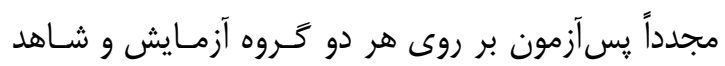

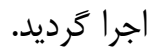

(WHOQOL-BREF: يرسـشنامه كيفيـت زندخى

World health organization quality of life- Brief) فرم خلاصه شده كيفيت زندگى سازمان بهداشت جهانى و

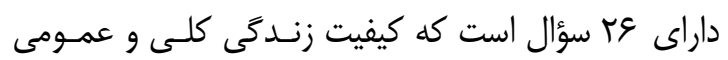

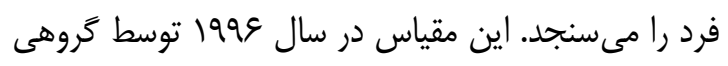

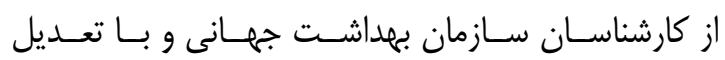

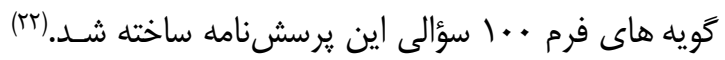

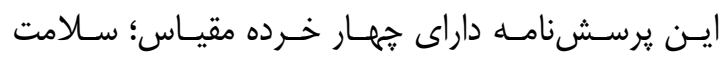

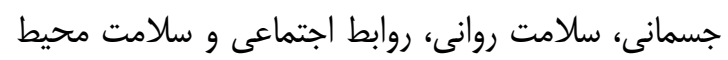

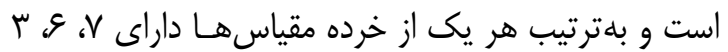
و ^ يرسش هستند. دو سؤال اول بـهـ هـيجيـــ از خـرده

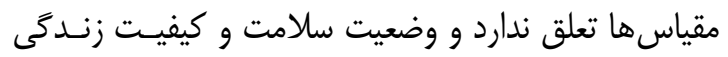

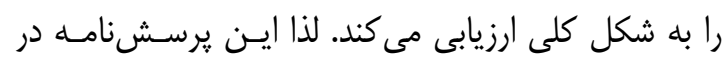

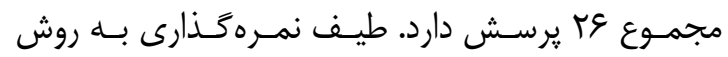

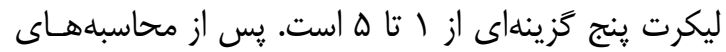

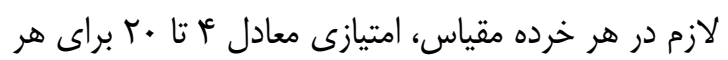

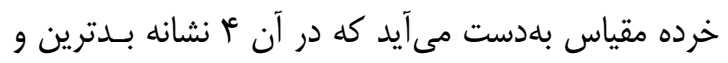

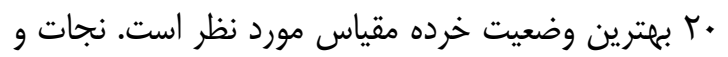
همكاران، بلمنظور بررسى پإيـايى يرسـشنامـهـ از روش
مىباشند. بلهَونهاى كـهـ بـين كـاهش كيفيـت زنـدكى و

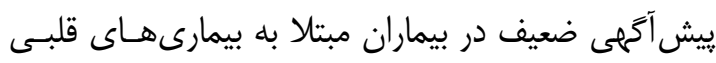

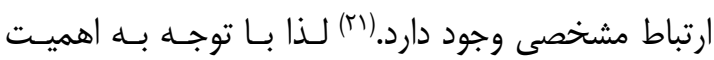

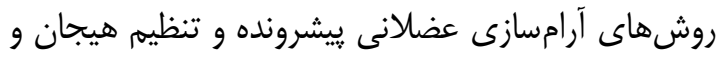

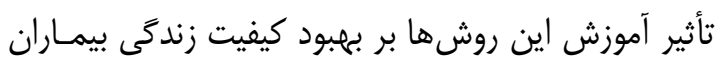

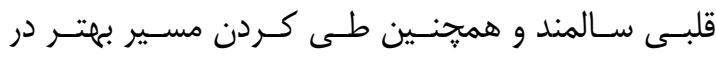

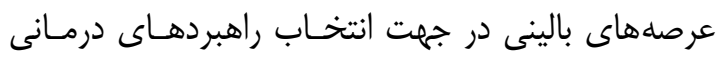

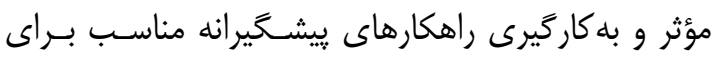

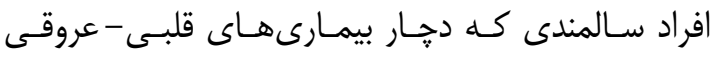

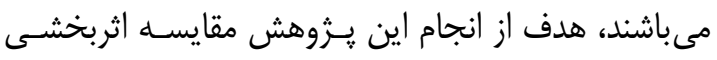

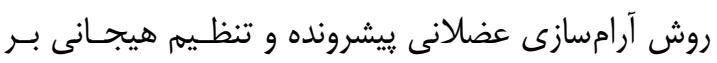
كيفيت زندگى بيماران قلبى سالمند است.

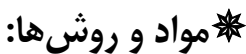

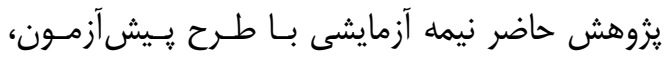

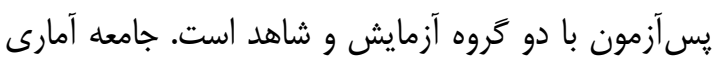

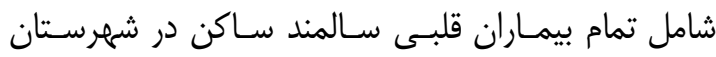

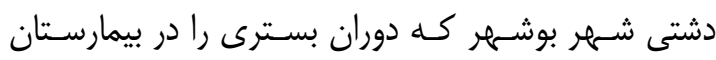

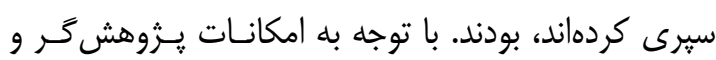

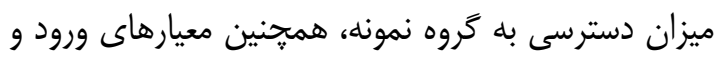

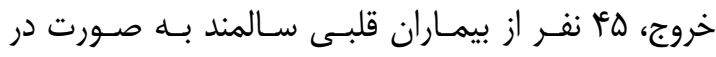
دسترس انتخاب شدند. معيارهاى ورود شامل: تمايل افراد جهت شركت در مطالعه، داشتن سابقه حـداقل يـكســال

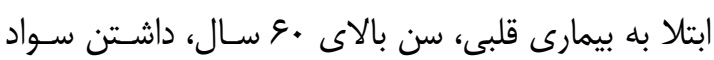

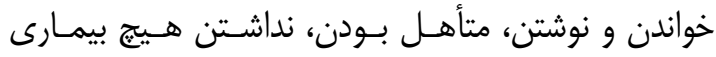

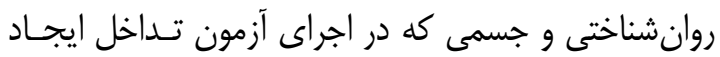

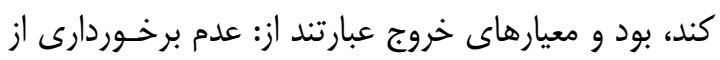

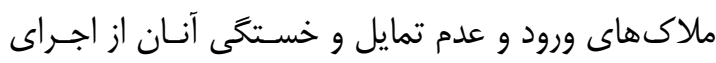

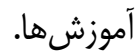
ابتدا به واسطه جدول اعداد تصادفى، افراد بـهـهـورت

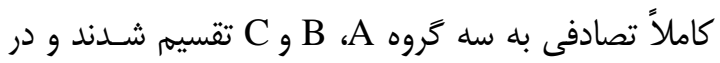

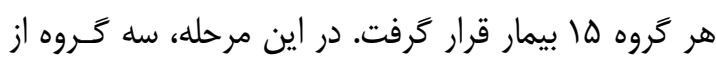
نظـر سـن، وضـعيت تحصـيلات و سـال هــاى بيمـارى

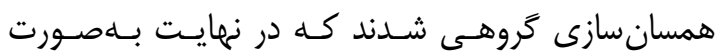


هيجـانى؛ جلســه دوم: معرفـى هيجـان هـاى بيمـارىزاو و

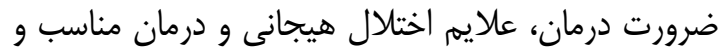

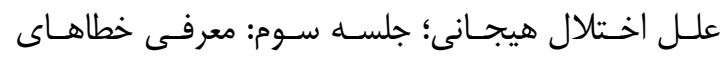

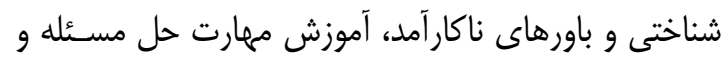

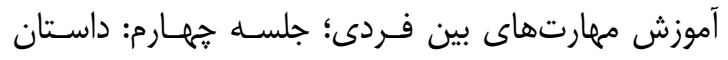
اختلال هاى هيجانى و تفسـير، شـناخت و بررسى افكـار

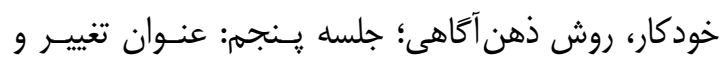

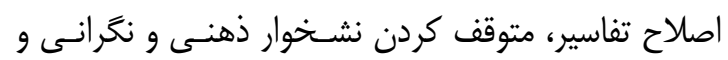

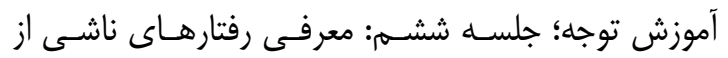

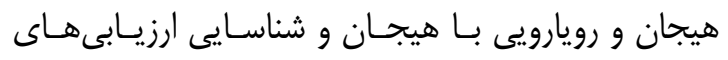

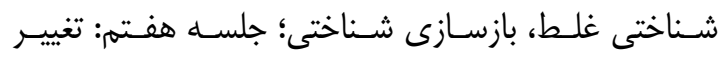

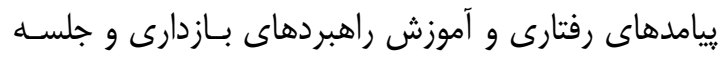

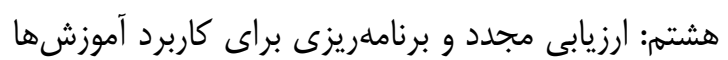

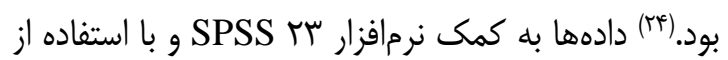

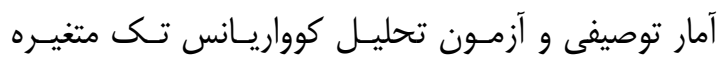

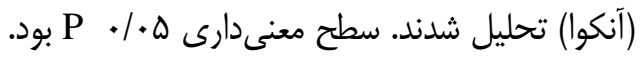

\section{每}

ميانگين و انحراف معيار نمرههاى كيفيت زندگى گروها

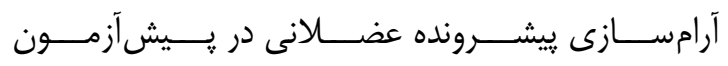
تف

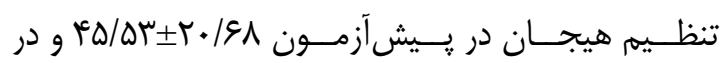

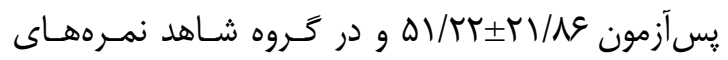

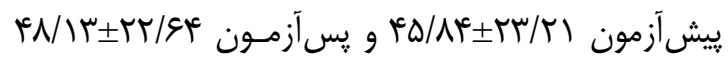

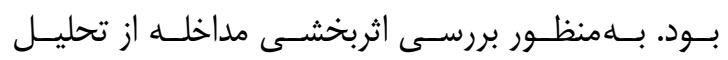

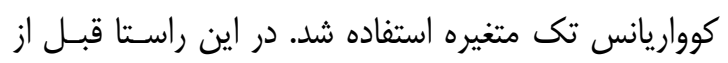

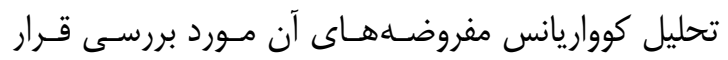

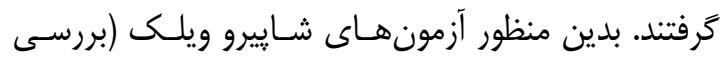

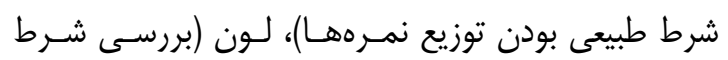

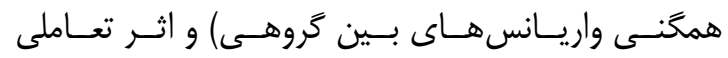

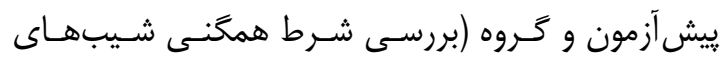

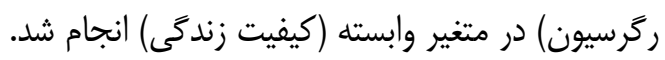

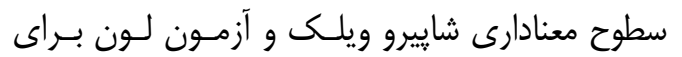

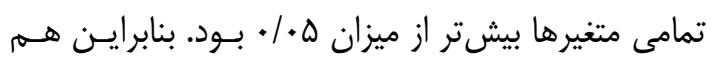

بازآزمايى استفاده كردند و ضريب همبستخى در هر ههبار

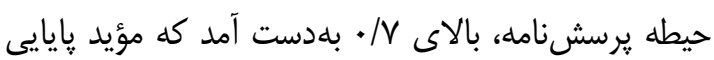

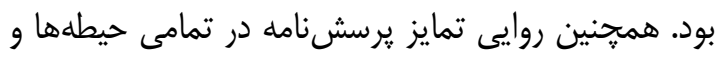

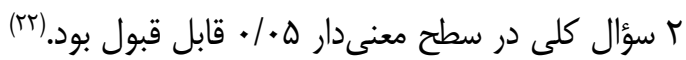

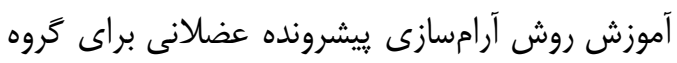

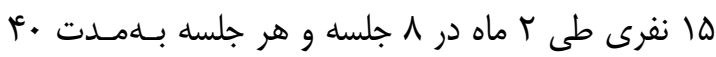

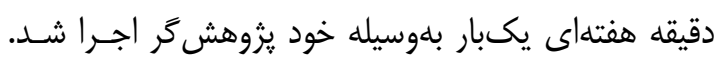

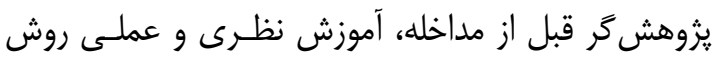

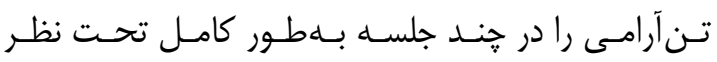

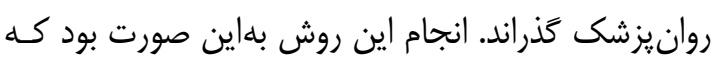

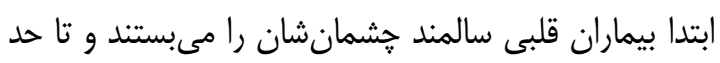

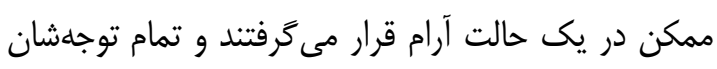

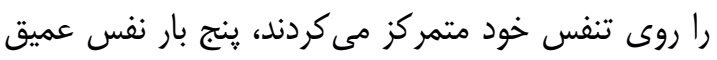

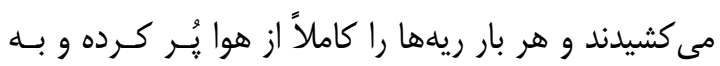

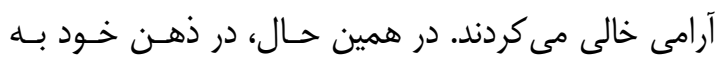

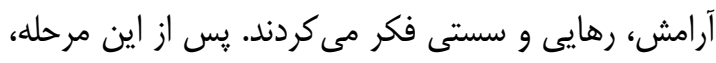

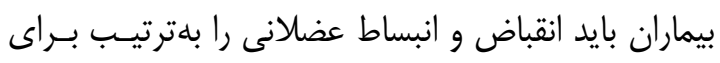

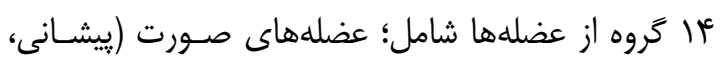

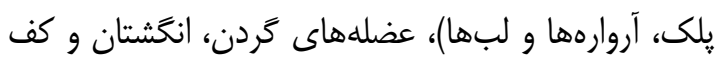

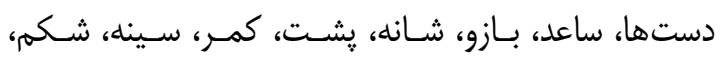

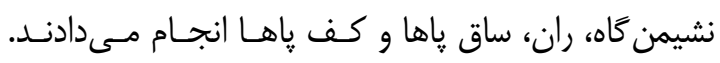

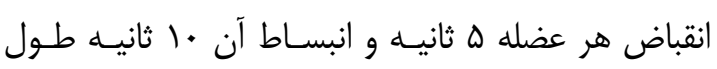
مى كشيد. همجنين در هنعام انقباض عضلهها، نبايد آنها

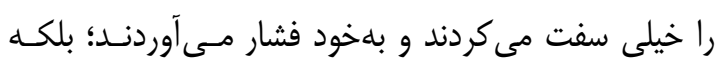
انقباض در حد معمولى كفايت مى كـرد. در انتهـا بيمـاران

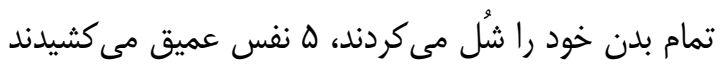

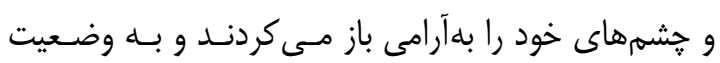
عادى برمى گشتند. (T)

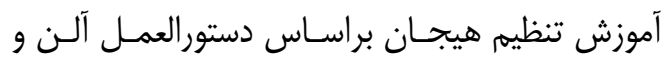

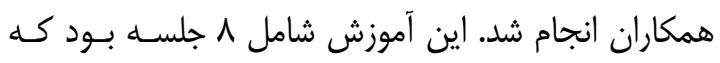

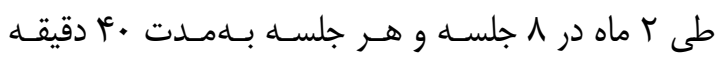

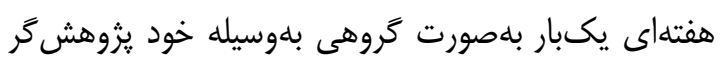

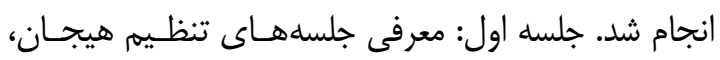
بيان هيجان طبيعى و هيجان مشكل آفرين و خودآكَاهى 
كروه آموزش عضلانى ييشرنده بـا حـروه تنظـيم هيجـان

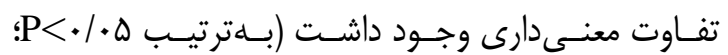

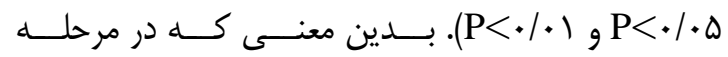

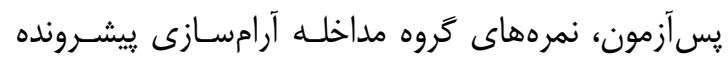

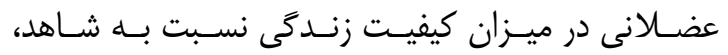

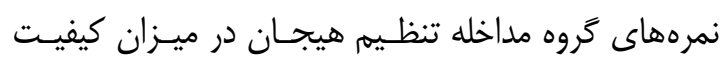

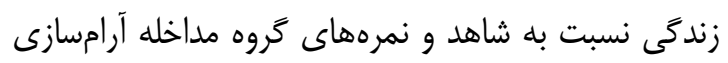

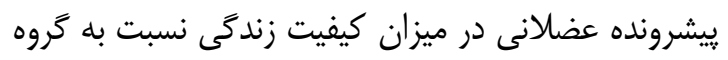

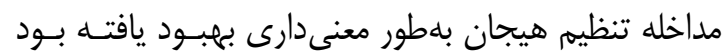
(جدولهاى شماره (، بو بَ).
نرمال بودن توزيع دادهها و هم همخنى واريانسهـا مـورد

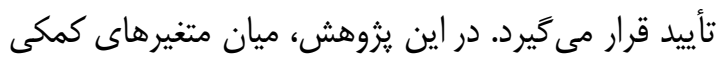

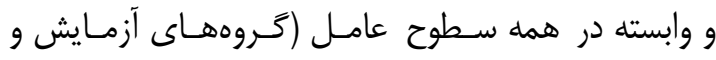

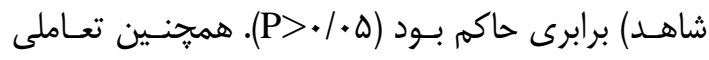

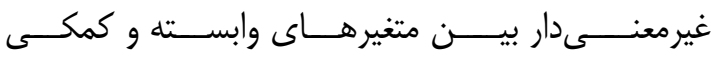

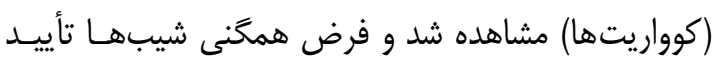
كرديد.

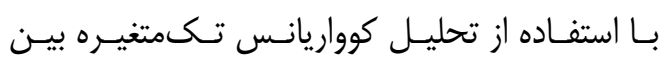

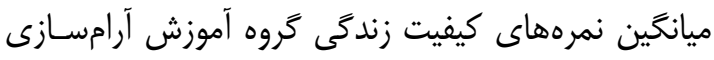

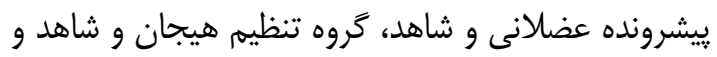

جدول ا - خلاصه نتايج تحليل آنكوا بر روى ميانكَين نمرههاى كيفيت زندَّى در تروه آموزش آرامسازى بيشرونده عضلانى و شاهد

\begin{tabular}{|c|c|c|c|c|c|c|}
\hline سطح معنىدارى & $\mathrm{F}$ & ميانكين مجذورات & درجه آزادى & مجموع مجذورات & شاخصها & \\
\hline $.1 \ldots *$ & 198/Ka & $1 . r \Delta V / .9$ & 1 & $1 . r \Delta V / .9$ & ييشآزمون & كيفيت زندگى \\
\hline \multirow[t]{2}{*}{.$/ \cdot r^{*}$} & ه/q & rqq/F. & 1 & rgq/f. & بين كروه & \\
\hline & & $g T / T \Delta$ & TV & $191 \cdot / 90$ & خطا & \\
\hline
\end{tabular}

جدول r - خلاصه نتايج تحليل آنكوا بر روى ميانكين نمرههاى كيفيت زندَى در تروه آموزش تنظيم هيجان و شاهد

\begin{tabular}{|c|c|c|c|c|c|c|}
\hline سطح معنىدارى & $\mathrm{F}$ & ميانگين مجذورات & درجه آزادى & مجموع مجذورات & شاخصها & \\
\hline $.1 \ldots *$ & $r \Delta V / r q$ & $15 \cdot 9 v / V{ }^{4}$ & 1 & $1 \pi \cdot 9 v / v{ }^{4}$ & ييشآزمون & كيفيت زندگى \\
\hline \multirow[t]{2}{*}{$.1 .4 *$} & D/q4 & WIV/R & 1 & سR/VIV & بين گروه & \\
\hline & & TN/G & tr & VIM/ID & خطا & \\
\hline
\end{tabular}

جدول بـ- خلاصه نتايج تحليل آنكوا بر روى ميانكَين نمرههاى كيفيت زندَى در تروه آموزش آرامسازى بيشرونده عضلانى و تروه آموزش تنظيم هيجان

\begin{tabular}{|c|c|c|c|c|c|c|}
\hline سطح معنى دارى & $\mathrm{F}$ & ميانكين مجذورات & درجه آزادى & مجموع مجذورات & شاخصها & \\
\hline.$/ \ldots *$ & $19 N / \cdot V$ & $1 .|8 Y / D|$ & 1 & $1 .|9 Y / D|$ & ييش آزمون & كيفيت زندگى \\
\hline $.1 .1 *$ & V/ra & $r V V / \& D$ & 1 & $r V V / F d$ & بين كروه & \\
\hline & & $\Delta 1 / \Gamma$. & TV & 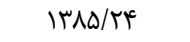 & خطا & \\
\hline
\end{tabular}

سطح معنى دارى * * 
كـاهش تــش، اضـطراب، تهـوع، اسـتفراغ و درد بــــــار

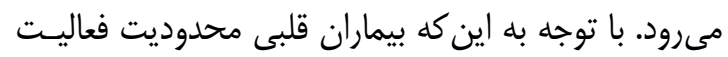

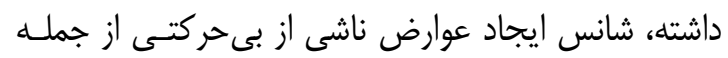

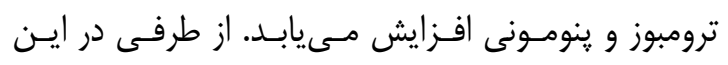

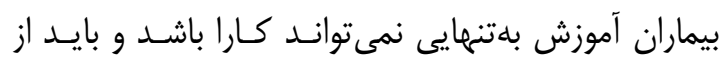

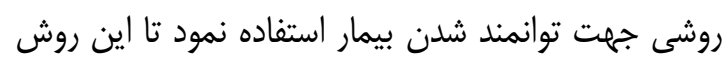

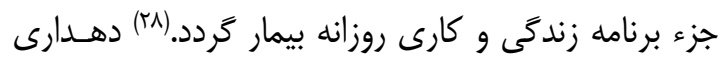

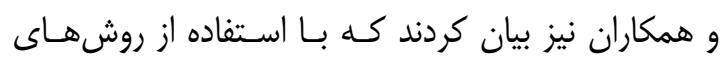

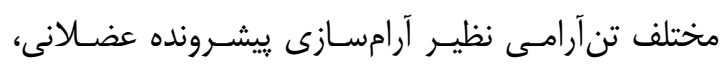

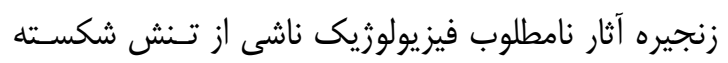

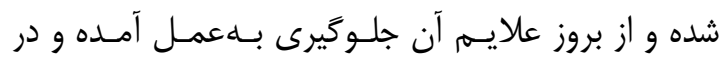
نهايت كيفيت زندخى افزايش مىيابد.

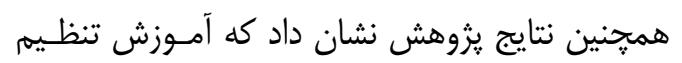
هيجان باعث بهبود كيفيت زندگى در بيماران قلبى سالمند

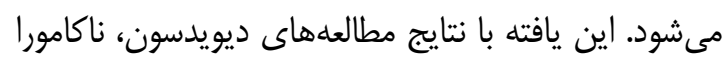

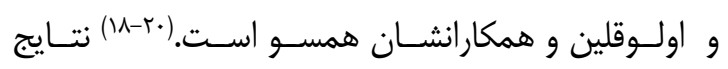
تحقيقها نشان مسى دهـــ ظرفيـت افـراد در تنظـيم مـؤثر

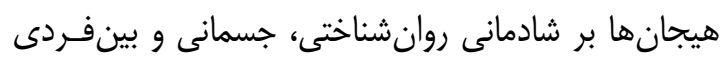

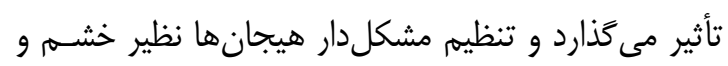

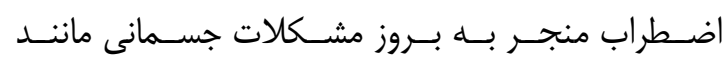

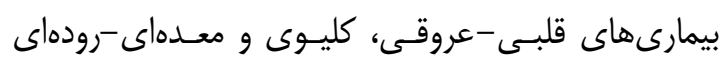

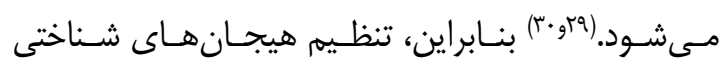

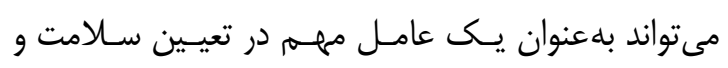

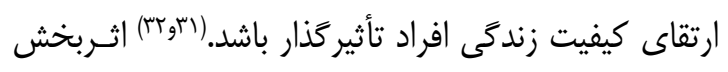

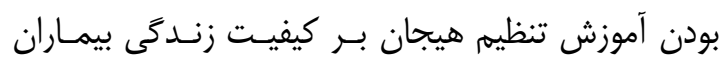
قلبى سالمند جنين تبيينيذير است كه تنظيم هيجان، فرد

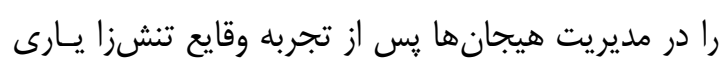

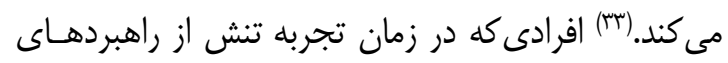
شناختى ساز كارانه تنظيم هيجان استفاده مى كنند با تغييـر

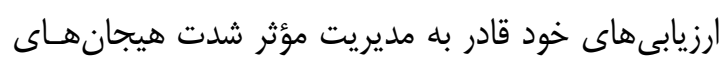

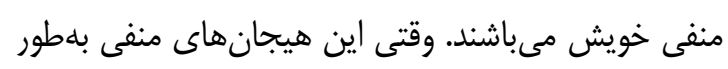

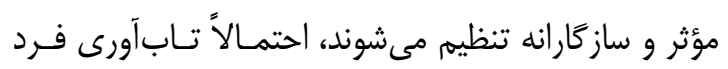
افزايش مى ميابد.(بَ)

\section{مث بحث و نتيجه}

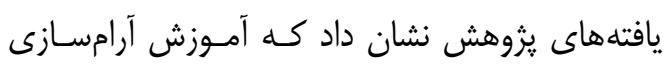
ييشرونده عضلانى باعث بهبود كيفيت زنداكى در بيمـاران

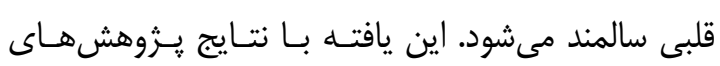

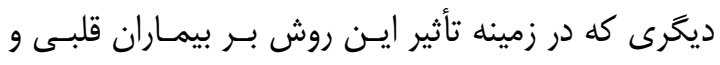

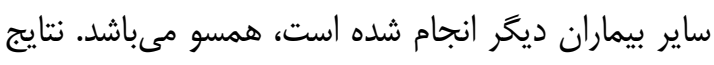

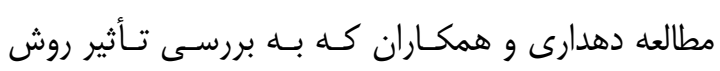

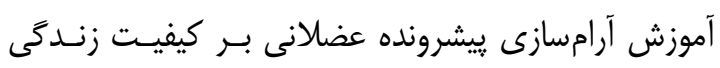

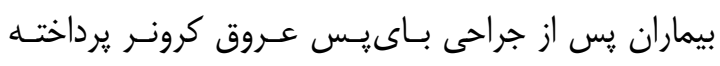

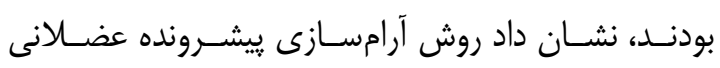

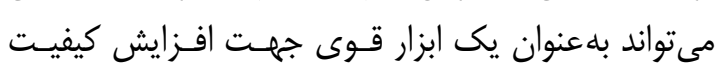

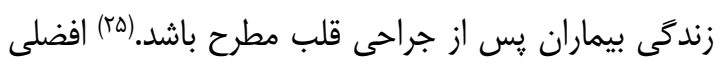

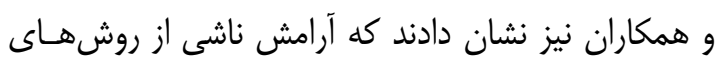

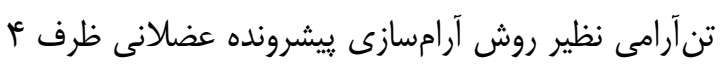

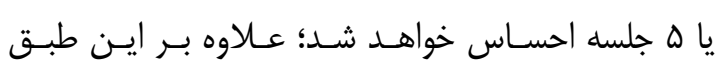

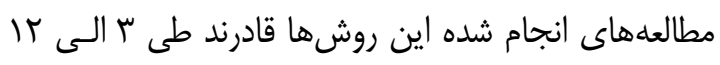

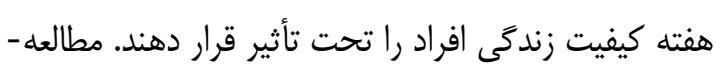

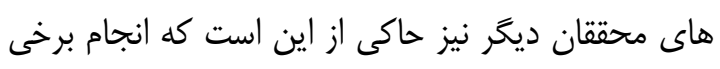

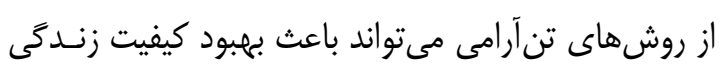

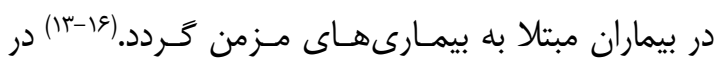

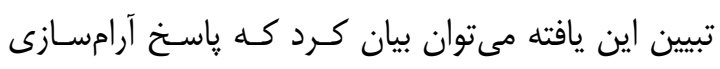

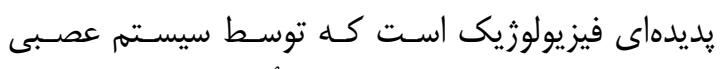

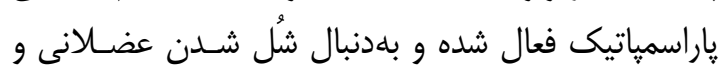

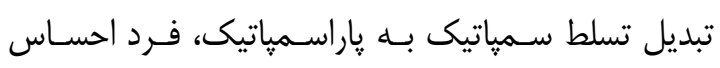

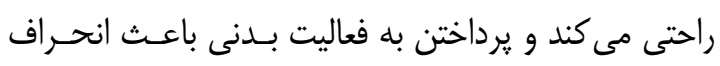

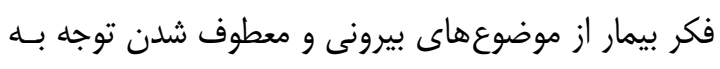

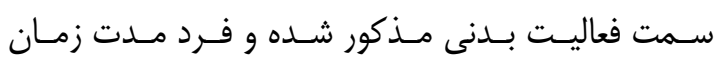

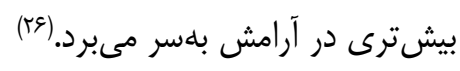

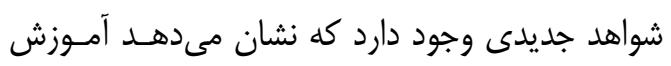

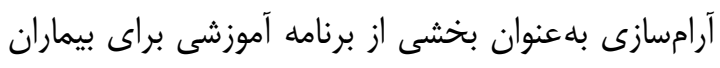

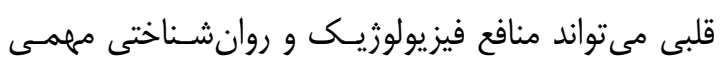

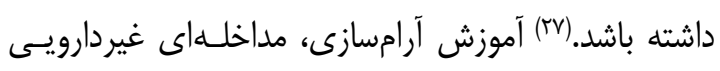

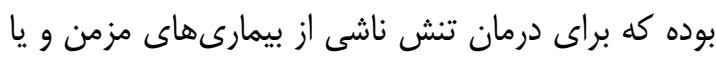

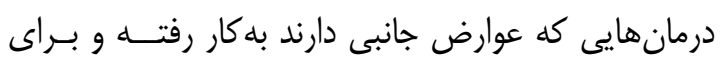


وجود نداشت. (1F) در مجموع مىتوان اظهار داشت با توجه بــه ايـنكـهـ

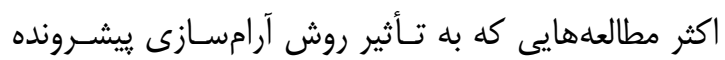

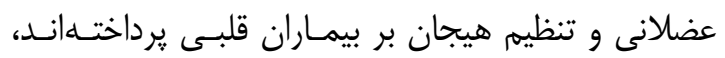

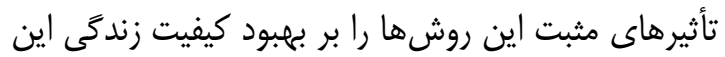

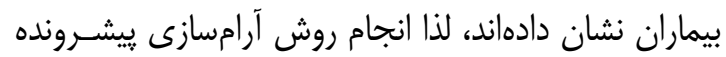
عضلانى و تنظيم هيجان توسـط بيمـاران قلبـى سـالمند

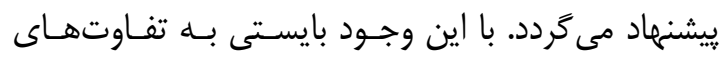
فردى و حالت روحى متفاوت نمونههاى تحت يوشـش در

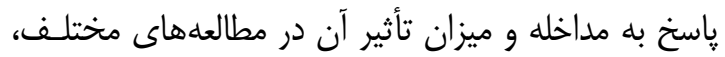

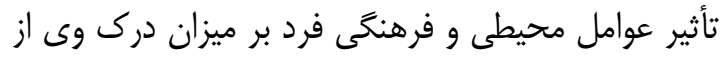

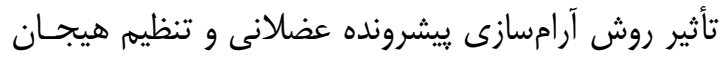
بر بهبود و ارتقاى كيفيت زندگى بيمار، توجه ويزه داشت. محدوديتهايى كه يثوهش حاضر با آنها روبرو بـود

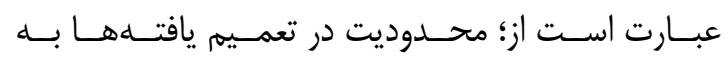

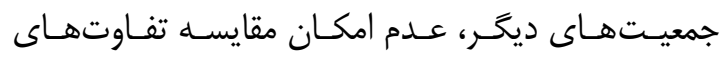

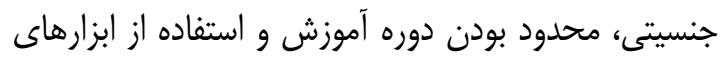

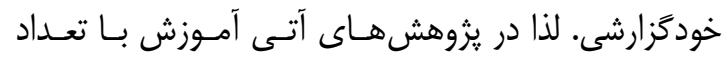
جلسههاى بيشتر و مدنظر قرار دادن تفاوتهاى جنسيتى إنى

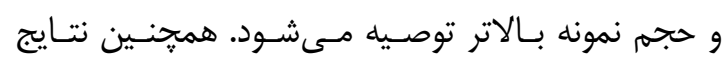

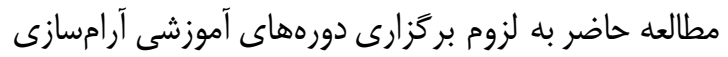

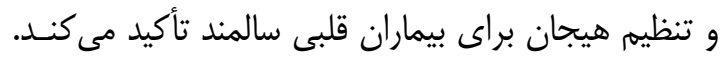

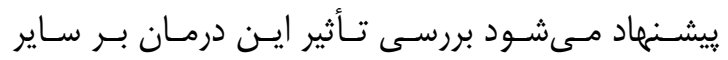

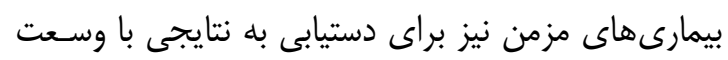
بيشتر بررسى شود.

\section{نو}

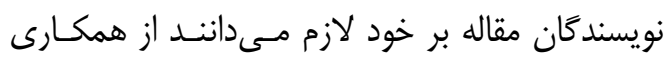

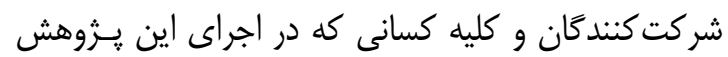
يارى نمودند، تقدير و قدردانى نمايند. اين مقاله بركرفته از ازئ

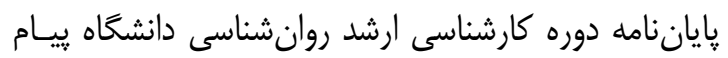

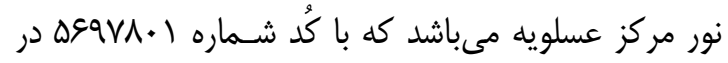
يزوهش كاه علوم و فن آورى اطلاعات ايران به ثبت رسيده
تنظـيم هيجـان سـازگًارانه، موجـب كـاهش علايـمم بيمارى مىشود، احساس رضايت و درك فـرد از سـلامت

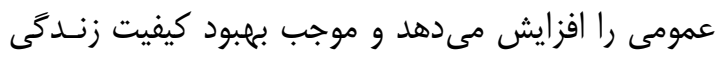

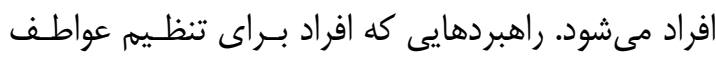

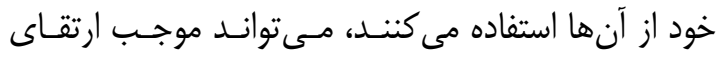

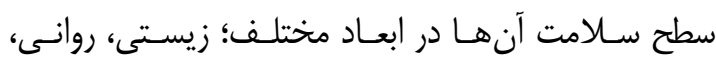

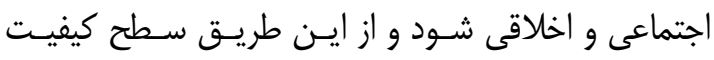

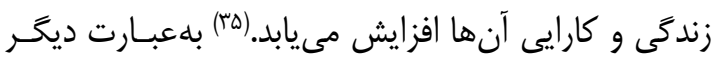

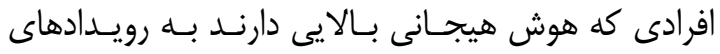
تنشزا بهعنوان جالش و فرصتى براى يادگيرى مىنكرند،

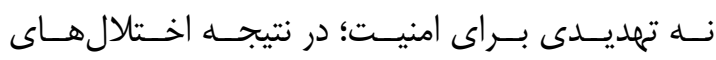

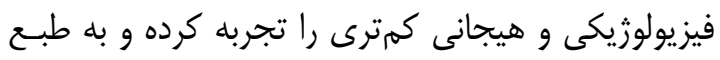
كيفيت زندگى بالاترى دارند. (\$2)

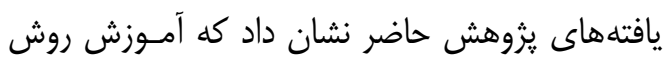

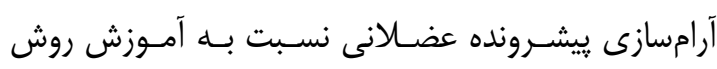

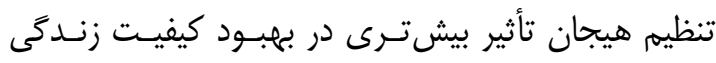

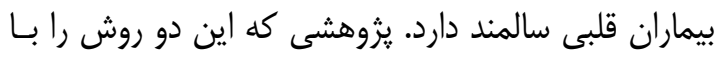
هم مقايسه كرده باشد يافت نشد. اكثر يزوهشها ئها هر كرد كدام

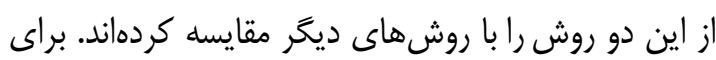

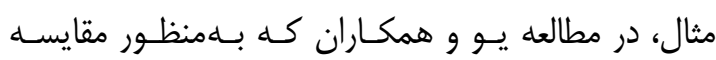

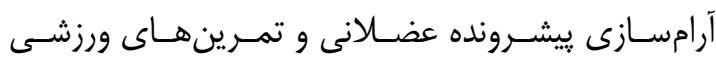

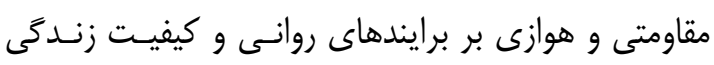

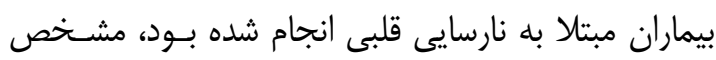

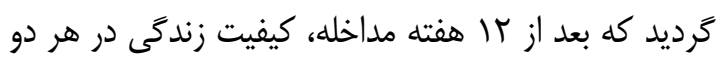

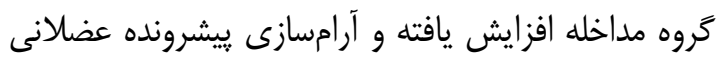

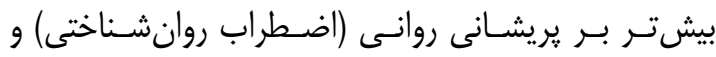

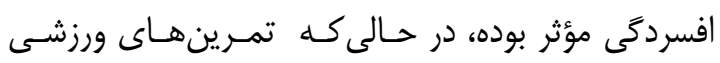

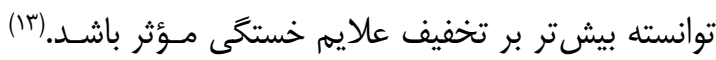

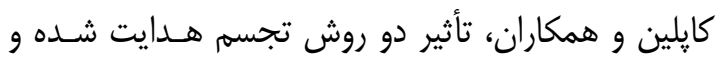

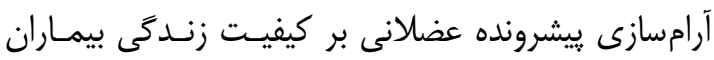

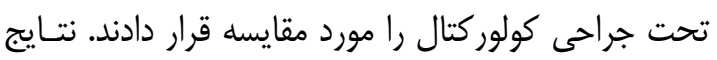

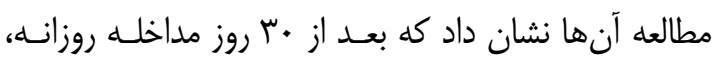

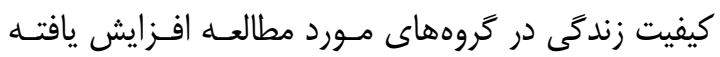

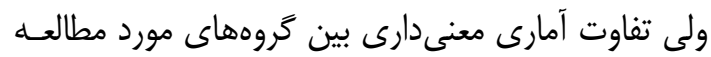


1. Abbasi A, Asayesh H, Hosseini SA, Ghorbani M, Abdollahi AA, Rouhi G, et al. The relationship between functional performance in patients with heart failure and quality of life. Iran South Med J 2010; 13(1): 31-40.

2. Straarup TS, Hausenloy DJ, Larsen JK. Cardiac troponins and volatile anaesthetics in coronary artery bypass graft surgery: a systematic review, meta-analysis and trial sequential analysis. Eur J Anaesthesiol 2016; 33(6): 396-407. doi: 10.1097/EJA. 0000000000000397.

3. Go AS, Mozaffarian D, Roger VL, Benjamin EJ, Berry JD, Blaha MJ, et al. Heart disease and stroke statistics-2014 update: a report from the American Heart Association. Circulation 2014; 129(3): e28e292. doi: 10.1161/01.cir.0000441139. 02102.80 .

4. Metzger M, Norton SA, Quinn JR, Gramling R. Patient and family members' perceptions of palliative care in heart failure. Heart Lung 2013; 42(2): 112-9. doi: 10.1016/ j.hrtlng.2012.11.002.

5. Rector TS, Anand IS, Cohn JN. Relationships between clinical assessments and patients' perceptions of the effects of heart failure on their quality of life. J Card Fail 2006; 12(2): 87-92. doi: 10.1016/j. cardfail.2005.10.002.

6. Sanders JJ, Robinson MT, Block SD. Factors impacting advance care planning among African Americans: results of a systematic integrated review. J Palliat Med 2016; 19(2): 202-27. doi: 10.1089/jpm.2015. 0325 .

7. Heydarnejad M, Hassanpour DA, Solati DK. Factors affecting quality of life in cancer

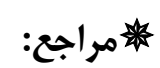

patients undergoing chemotherapy. Afr Health Sci 2011; 11(2): 266-70.

8. Burack OR, Weiner AS, Reinhardt JP, Annunziato RA. What matters most to nursing home elders: quality of life in the nursing home. J Am Med Dir Assoc 2012; 13(1): 48-53. doi: 10.1016/j.jamda.2010.08. 002.

9. Dehkordi AH, Heydarnejad S. Effect of relaxation on the level of nursing internship studentsl' stress. J Hainan Med College 2010; 16(1): 20-2.

10. Bashar FR, Vahedian-Azimi A, Salesi M, Hosseini SM. The effect of progressive muscle relaxation on the outcomes of myocardial infarction: review study. J Mil Med 2017; 19(4): 326-35. [In Persian]

11. Avazeh A, Hajiesmaeili M, VahedianAzimi A, Naderi A, Madani S, Jafarabadi M. Effect of progressive muscle relaxation on patients lifestyle with myocardial infarction: a double-blinded randomized controlled clinical trial. J Knowledge and Health 2015; 10(3): 1-8. doi: 10.22100/jkh.v10i3.635. [In Persian]

12. Pathak P, Mahal R, Kohli A, Nimbran V. Progressive Muscle Relaxation: An adjuvant therapy for reducing pain and fatigue among hospitalized cancer patients receiving radiotherapy. International $\mathrm{J}$ Advanced Nursing Studies 2013; 2(2): 58. doi: 10. 14419/ijans.v2i2.715.

13. Yoo HJ, Ahn SH, Kim SB, Kim WK, Han OS. Efficacy of progressive muscle relaxation training and guided imagery in reducing chemotherapy side effects in patients with breast cancer and in improving their quality of life. Support Care Cancer 2005; 13(10): 826-33. doi: 10.1007/s00520-005-0806-7. 
14. Koplin G, Müller V, Heise G, Pratschke J, Schwenk W, Haase O. Effects of psychological interventions and patients' affect on short-term quality of life in patients undergoing colorectal surgery. Cancer Med 2016; 5(7): 1502-9. doi: 10.1002/cam4.739.

15. Mazloomy Mahmoodabad S, Zolghadr R, Mirhossaini J, Yasini Ardakani S, Fallahzadeh H, Askarifar J. Effect of Benson relaxation education on quality of life in patients after open heart surgery in Yazd city. Toloo e Behdasht 2014; 12(4): 88-96. [In Persian]

16. Afzali S, Masoudi R, Etemadifar S, Moradi M, Moghaddasi J. The effect of progressive muscle relaxation program (PMR) on anxiety of patients undergoing coronary heart angiography. J Shahrekord Univ Med Sci 2009; 11(3): 77-84. [In Persian]

17. Aldao A, Nolen-Hoeksema S, Schweizer S. Emotion-regulation strategies across psychopathology: a meta-analytic review. Clin Psychol Rev 2010; 30(2): 217-37. doi: 10.1016/j.cpr.2009.11.004.

18. Davidson KW, Mostofsky E, Whang W. Don't worry, be happy: positive affect and reduced 10-year incident coronary heart disease: the Canadian Nova Scotia Health Survey. Eur Heart J 2010; 31(9): 1065-70. doi: 10.1093/eurheartj/ehp603.

19. Nakamura S, Kato K, Yoshida A, Fukuma $\mathrm{N}$, Okumura $\mathrm{Y}$, Ito $\mathrm{H}$, et al. Prognostic value of depression, anxiety, and anger in hospitalized cardiovascular disease patients for predicting adverse cardiac outcomes. Am J Cardiol 2013; 111(10): 1432-6. doi: 10. 1016/j.amjcard.2013.01.293.

20. O'Loughlin C, Murphy NF, Conlon C, O'Donovan A, Ledwidge M, McDonald K. Quality of life predicts outcome in a heart failure disease management program. Int $\mathrm{J}$ Cardiol 2010; 139(1): 60-7. doi: 10.1016/j. ijcard.2008.09.003.

21. Ismaili Z, Zaybakhsh Tabari S, Vaezzadeh N, Mohammadpour R. Evaluation of patients' quality of life after cardiopulmonary surgery in Sari, Iran. J Mazandaran Univ Med Sci 2007; 17(61): 170-4. [In Persian]

22. Nejat S, Montazeri A, Holakouie Naieni

K, Mohammad K, Majdzadeh SR. The World Health Organization Quality of Life (WHOQOL-BREF) questionnaire: Translation and validation study of the Iranian version. J Sch Public Health Inst Public Health Res 2006; 4(4): 1-12. [In Persian]

23. Jariani M, Saki M, Momeni N, Ebrahimzade F, Seydian A. The effect of progressive muscle relaxation techniques on anxiety in Patients with myocardial infarction. Yafteh 2011; 13(3): 22-30. [In Persian]

24. Allen LB, McHugh RK, Barlow DH. Clinical handbook of psychological disorders: A step-by-step treatment manual. 4th ed. New York: Guilford Press; 2008; 216-49

25. Dehdari T, Heidarnia A, Ramezankhani A, Sadeghian S, Ghofranipour F. Effects of progressive muscular relaxation training on quality of life in anxious patients after coronary artery bypass graft surgery. Indian J Med Res 2009; 129(5): 603-8.

26. Van Dixhoorn J, White A. Relaxation therapy for rehabilitation and prevention in ischaemic heart disease: a systematic review and meta-analysis. Eur J Cardiovasc Prev Rehabil 2005; 12(3): 193-202. doi: 10.1097/ 01.hjr.0000166451.38593.de

27. Robert JP, Lewin - David R, Thompson

R. Trial of the effects of an advice and 
relaxation tape within the first 24 hours of admission to hospital with acute myocardial infarction. Int J Cardiol 2002; 82: 107-14.

28. Cheung YL, Molassiotis A, Chang AM. The effect of progressive muscle relaxation training on anxiety and quality of life after stoma surgery in colorectal cancer patients. Psychooncology 2003; 12(3): 254-66.

29. Gresham D, Gullone E. Emotion regulation strategy use in children and adolescents: the explanatory roles of personality and attachment. Pers Individ Dif 2012; 52(5): 616-21. doi: 10.1016/j.paid. 2011.12.016.

30. Amone-P'Olak K, Garnefski N, Kraaij V. Adolescents caught between fires: Cognitive emotion regulation in response to war experiences in Northern Uganda. J Adolesc 2007; 30(4): 655-69. doi: 10.1016/j. adolescence.2006.05.004.

31. Lamé IE,Peters ML, Vlaeyen JW, Kleef Mv, Patijn J. Quality of life in chronic pain is more associated with beliefs about pain, than with pain intensity. Eur J Pain 2005; 9(1): 1524. doi: 10.1016/j.ejpain.2004.02.006.
32. Cicchetti DE, Cohen DJ. Developmental psychopathology: Theory and method. 2nd ed. New York: Wiley Press; 2006. 3-20.

33. Garnefski N, Rieffe C, Jellesma F, Terwogt MM, Kraaij V. Cognitive emotion regulation strategies and emotional problems in 9-11-year-old children: the development of an instrument. Eur Child Adolesc Psychiatry 2007; 16(1): 1-9.

34. Troy AS, Mauss IB. Resilience in the face of stress: emotion regulation as a protective factor. Resilience and Mental Health 2011; 1(2): 30-44. doi: 10.1017/ CBO9780511994791.004.

35. Salehi-Morekani B. Evaluation and comparison of emotional self-regulation strategies among students with anxiety and depression disorders with normal students in Isfahan. University of Al-Zahra 2006.

36. Hosseinian S, Ghasemzadeh S, Niknam M. Prediction of quality of life in female teachers on the basis of emotional and spiritual intelligence variables. Quarterly $\mathrm{J}$ Career Organizational Counsel 2011; 3(9): 42-60. [In Persian] 